\title{
Neurology in the psychiatric patient: how to think about differentials in altered mental status and diagnoses not to miss - CORRIGENDUM
}

\section{Jonathan McLaughlin \& Tim Young}

doi: 10.1192/bja.2021.67. Published by Cambridge University Press, 29th November 2021.

The authors would like to amend the biography for Tim Young to read as follows:

Tim Young has been a locum consultant neurologist at University Hospital Lewisham, Lewisham and Greenwich NHS Trust in London and and currently works as an associate professor (teaching) and course co- director of the Clinical Neurology by Distance Learning MSc/Diploma/Postgraduate Certificate course at the Queen Square Institute of Neurology, UCL, London, UK.

The authors apologise for this error.

\section{Reference}

McLaughlin J, Young T (2021). Neurology in the psychiatric patient: how to think about differentials in altered mental status and diagnoses not to miss. BJPsych Advances, 1-13. doi: 10.1192/bja.2021.67 